\title{
Arquitectura
}




\section{Proyecto de rehabilitación de un edificio subutilizado para generar vivienda en el área central de la ciudad de San José}

Lic. Felipe Pina Castillo, Arquitecto

Invitado nacional.

Profesional independiente

pinafeli@gmail.com

Recibido: marzo del 2016

Aceptado: mayo del 2016

Arquitectura Reseña 


\section{Resumen}

Reseña del proyecto arquitectónico titulado "Rehabilitación de un edificio subutilizado para generar vivienda en el área central de San José”. El tema del proyecto tiene la voluntad de ser una referencia para el proceso de ejecución del Plan de Regeneración y Repoblamiento de la ciudad de San José. Esta investigación se llevó a cabo como parte del proyecto final de graduación para optar por el grado de Licenciatura en Arquitectura y Urbanismo del Instituto Tecnológico de Costa Rica.

Palabras clave: reciclaje de edificios; regeneración urbana; repoblamiento; San José.

\section{Abstract}

This is a review of the architectural project entitled "Rehabilitation of vacant buildings to generate housing in the central area of San José". The subject of the project described here is intended to be a point of reference for the implementation an area of a Regeneration and Repopulation Plan of the city of San Jose. This research was undertaken as part of final graduation project in Architecture and Urbanism at the Costa Rica Institute of Technology.

Keywords: recycling of buildings; urban regeneration; repopulation; San José. 


\title{
Proyecto de rehabilitación de un edificio subutilizado para generar vivienda en el área central de la ciudad de San José
}

\author{
Felipe Pina Castillo ${ }^{1}$
}

Los cambios en los patrones de consumo de los grupos de población de mayor poder adquisitivo respecto a la necesidad de vivienda, han promovido un acelerado crecimiento periférico del área metropolitana y el creciente proceso de deterioro, obsolescencia y despoblamiento del área central de la Gran Área Metropolitana de Costa Rica (G.A.M.) El despoblamiento del centro de la ciudad de San José ha generado un aumento de la inseguridad y de los problemas sociales en general, y sobre todo ha conformado un esquema insostenible para el Estado con graves efectos sobre el medio ambiente.

Esta emigración de la población a las zonas periféricas se evidencia al consultar datos demográficos sobre la ciudad de San José, en sus cuatro distritos centrales donde se evidencia que la ciudad ha perdido en un lapso de 38 años, casi el 50\% de sus habitantes. Según el último censo que registra el Instituto Nacional de Estadística y Censos INEC ${ }^{2}$, que data del año 2011, el cantón de San José reportó una población total de 288054 habitantes, número muy por debajo del registrado durante el censo del 2000, en el que la cifra fue de 309 672. Como se demuestra, el área central de la ciudad de San José, viene presenciando una clara dispersión urbana debido a una migración de sus habitantes hacia las zonas periféricas dejando abandonados o subutilizados muchos edificios y convirtiendo a la mayor parte de la ciudad meramente en una zona de paso de fuentes de empleo e intercambio de flujo.

La recuperación de los centros urbanos ha sido una preocupación generalizada en los últimos tiempos en muchas ciudades alrededor del mundo y Costa Rica no es la excepción.

Se han dado múltiples esfuerzos por darle a San José una fisonomía más ordenada, sostenible, inclusiva y ecológica, más amigable con el habitante urbano. Las pautas de

\footnotetext{
1 Arquitecto (2016) por el Tecnológico de Costa Rica. Cuenta con 9 años de experiencia, trabajando en varias oficinas como asistente en proyectos, labores de desarrollo y maquetas. También se ha encargado de estudios preliminares, conceptualización de proyectos, diseños esquemáticos y modelado 3D. Actualmente trabaja en la oficina de arquitectura Tándem Arquitectura.

2 Se observa en la información obtenida en el Instituto Nacional de Estadística y Censos (INEC), que de acuerdo al Censo de 2011, San José, tenía una población de 47.165 habitantes, distribuida de la siguiente manera: Carmen: 2702 Hab.; Merced: 12.257 Hab.; Hospital: 19.270 Hab.; y Catedral: 12.936 Hab, (ver gráfico 2). En el 2000, el Censo registró 56.441 habitantes en el mismo sector, en 1984, 69.976 habitantes, y en 1973, el censo registra 91.659 habitantes (ver gráfico 1), lo que demuestra una tendencia de pérdida poblacional. Sin embargo, estos cuatro distritos a pesar de estar en el cantón con mayor cantidad de población, como se mencionó anteriormente, son los de menor densidad de población.
} 
este nuevo emprendimiento las havenido marcando el Consejo Nacional dePlanificación Urbana (Plan GAM 2013) y la Municipalidad de San José (Plan de Regeneración y Repoblamiento de San José), a través de estos y otros planes estratégicos que buscan la mejora del entorno urbano de la ciudad. Estas pautas estimulan la creación de proyectos que mejoren la calidad de vida de los habitantes de las áreas urbanas, y por consiguiente generen arraigo, sentido de pertenencia, seguridad y el repoblamiento de la ciudad entre otros beneficios de las políticas de repoblamiento. Junto a las instituciones ya señaladas, se suma la participación de la Secretaría Técnica del Plan Nacional de Desarrollo Urbano (Plan GAM 2013 - 2030), coordinada por el Instituto Tecnológico de Costa Rica 3 .

La Municipalidad de San José, como la principal institución reguladora del centro capitalino, con el apoyo del Ministerio de Vivienda y Asentamientos Humanos (MIVAH), constituyó la Comisión Interinstitucional del Programa de Regeneración y Repoblamiento de los cuatro distritos centrales del cantón central de la provincia de San José para abordar el tema. Como resultado de este esfuerzo se dictaron una serie de pautas fundamentales, que vienen a incentivar un modelo vertical y compacto de ciudad que haga un uso racional de los recursos limitados, como el espacio y la infraestructura. Todo esto en concordancia con el objetivo de compactación de las Centralidades Densas Integrales (CDI), que maneja el Plan GAM 2013 - 2030. Este último también considera la vivienda vertical el centro del sistema urbano que funciona como un recurso estratégico del modelo, complementándose con los conceptos de compacidad y uso mixto del suelo. El Plan GAM 2013 - 2030, no solo incentiva la creación de más y mejores viviendas, sino que propone la promoción y el incentivo a los proyectos de rehabilitación de edificios preexistentes, independientemente de su uso anterior ${ }^{4}$

La puesta en valor y recuperación del área central de San José es de conveniencia para toda la comunidad y se presenta como una gran oportunidad de desarrollo para la ciudad, la cual está bien dotada de infraestructura y espacios públicos, servicios y equipamientos que justifican una regeneración urbana.

El centro de San José es uno de los puntos más dinámicos de la economía, alojando una variedad de instituciones y servicios que incluye educación, deporte, arte, patrimonio,

\footnotetext{
3 Uno de ellos es el reciente proyecto del Centro Histórico de San José, promovido por la Municipalidad de San José, con el apoyo del Ministerio de Cultura y Juventud, del Ministerio de Turismo y la Cámara de Hoteles, con el fin de reivindicar el valor simbólico, arquitectónico, cultural y turístico del casco urbano, mejorando así su competitividad, su sostenibilidad y sus alternativas de progreso urbano, económico y social.

4 Estudios técnicos elaborados por la dirección de urbanismo y vivienda del Ayuntamiento de Madrid en el año 2009, demostraron que: "Rehabilitar un edificio supone en la mayoría de los casos, un ahorro energético del 60\% con respecto de derribarlo y volver a construirlo; además evita numerosos impactos ambientales asociados".
} 
cultura, salud, vivienda, ocio, transporte público, entre otros. Esta suma de factores y otros, como la congestión del tránsito y el aumento de los tiempos de recorrido pueden afectar positivamente las preferencias de los consumidores por volver al centro de la capital.

El proyecto de rehabilitación de un edificio subutilizado para generar vivienda en el área central de la ciudad de San José tuvo como objetivo general revertir la tendencia hacia el despoblamiento y el deterioro de la capital y formar parte de una solución integral al problema de la proliferación de activos inmobiliarios desocupados o subutilizados, reconociendo el enorme potencial que tienen para ser transformados y utilizados como edificios residenciales.

Es así como la rehabilitación de edificios desocupados, se vuelve un imperativo por la simple razón de que reconvertir un edificio es un proceso más baratoy menos complicado que construirlo a partir de cero. La rehabilitación de los edificios desocupados existentes es, por encima de todo, una opción lógica desde el punto de vista económico, un proceso habitual a lo largo de la historia y más allá de esto, ofrece las ventajas de habitar un centro urbano en términos de movilidad y calidad de vida.

No solo la vivienda colectiva vertical, sino también la rehabilitación de edificios desocupados se perciben como un gran detonante del mejoramiento urbano de nuestras ciudades. El repoblamiento de los centros urbanos responde a la necesidad de aumentar el rendimiento de los impuestos inmobiliarios y los impuestos a los servicios con los que se financia el mantenimiento y mejoramiento de la infraestructura y los espacios públicos centrales. El repoblamiento es una forma de aumentar la densidad de población, que al mismo tiempo, busca un mayor aprovechamiento del suelo e infraestructura existente y la intensificación de la vida urbana, que supone, la permanencia de las personas en los espacios públicos, los encuentros para socializar y la oportunidad de establecer arraigo, sentido de identidad entre los habitantes y la ciudad.

Ante esta coyuntura, se describe el problema de investigación mediante la formulación de la siguiente pregunta de investigación: ¿Es la rehabilitación de edificios subutilizados para uso residencial una alternativa viable para, no solo mitigar la pérdida de población en el centro de San José, sino ayudar a mejorar su calidad general de vida?

El área geográfica de intervención del proyecto corresponde al territorio del cantón de San José, específicamente en los cuatro distritos centrales, llámense Carmen, Merced, 
Hospital y Catedral. Estos cuatro distritos conforman la Zona de Renovación Urbana (ZRU), en coincidencia con el Decreto $\mathrm{N}^{\circ}$ 31730-MIDEPLAN-MIVAH del 3 de febrero del 2004 y son los centros de población más antiguos y mejor dotados de infraestructura de la GAM. La Zona de Renovación Urbana evidencia diferentes características que les permite trabajar como un sistema de servicios y programas complementarios, lo que les genera una personalidad urbanística y funcional muy característica y por tanto objeto de estudio.

Si bien el proyecto de rehabilitación de un edificio subutilizado para generar vivienda en el área central de la ciudad de San José consideró entre sus objetivos realizar un inventario de los activos inmobiliarios desocupados y/o subutilizados, llevar a cabo un estudio del funcionamiento del mercado inmobiliario actual, desarrollar un análisis financiero de la viabilidad del proyecto; en esta reseña se mostrará el desarrollo del anteproyecto arquitectónico de la rehabilitación del edificio Plaza de La Artillería ubicado en el distrito Merced, Avenida Central, Calle 4, como una posible solución al repoblamiento de la ciudad en el marco del modelo de ciudad compacta.

Las imágenes que se muestran a continuación, describen la propuesta de rehabilitación que consistió en realizar el diseño de tres posibles escenarios de rehabilitación del edificio en mención con el fin de demostrar y/o justificar cuál de estos escenarios ofrecía las mejores condiciones arquitectónicas y financieras dentro de la preexistencia dada por el inmueble. La principal diferencia entre las tres alternativas, consiste en visualizar tanto tres variantes en la estructura de la circulación principal (lateral, central y exterior); como también tres tipologías de apartamento, de una, dos y tres habitaciones, se determinó al final que la propuesta de diseño para la rehabilitación del edificio se llevaría a cabo con el escenario 3, que corresponde al diseño de una pasarela exterior como circulación principal.

Este escenario representó la mayor rentabilidad y posibles utilidades netas. Igualmente a nivel arquitectónico es la que contó con un mejor uso del espacio en general, con doble orientación en todas las unidades, ofreciendo una mejor iluminación y ventilación natural.

Globalmente no se analizó la capacidad de la estructura del edificio, sin embargo se propusieron mejoras locales a elementos para evitar comportamientos adversos durante un sismo fuerte o en general. 
En la propuesta de rehabilitación no se incluyeron los primeros dos niveles, que corresponden al lobby y a los locales comerciales, por estar en buenas condiciones y/o se estaban haciendo las mejoras por parte del propietario y con respecto al tercer nivel que corresponde al estacionamiento, solo se realizó un reacomodo de los parqueos y las circulaciones para estar en regla.

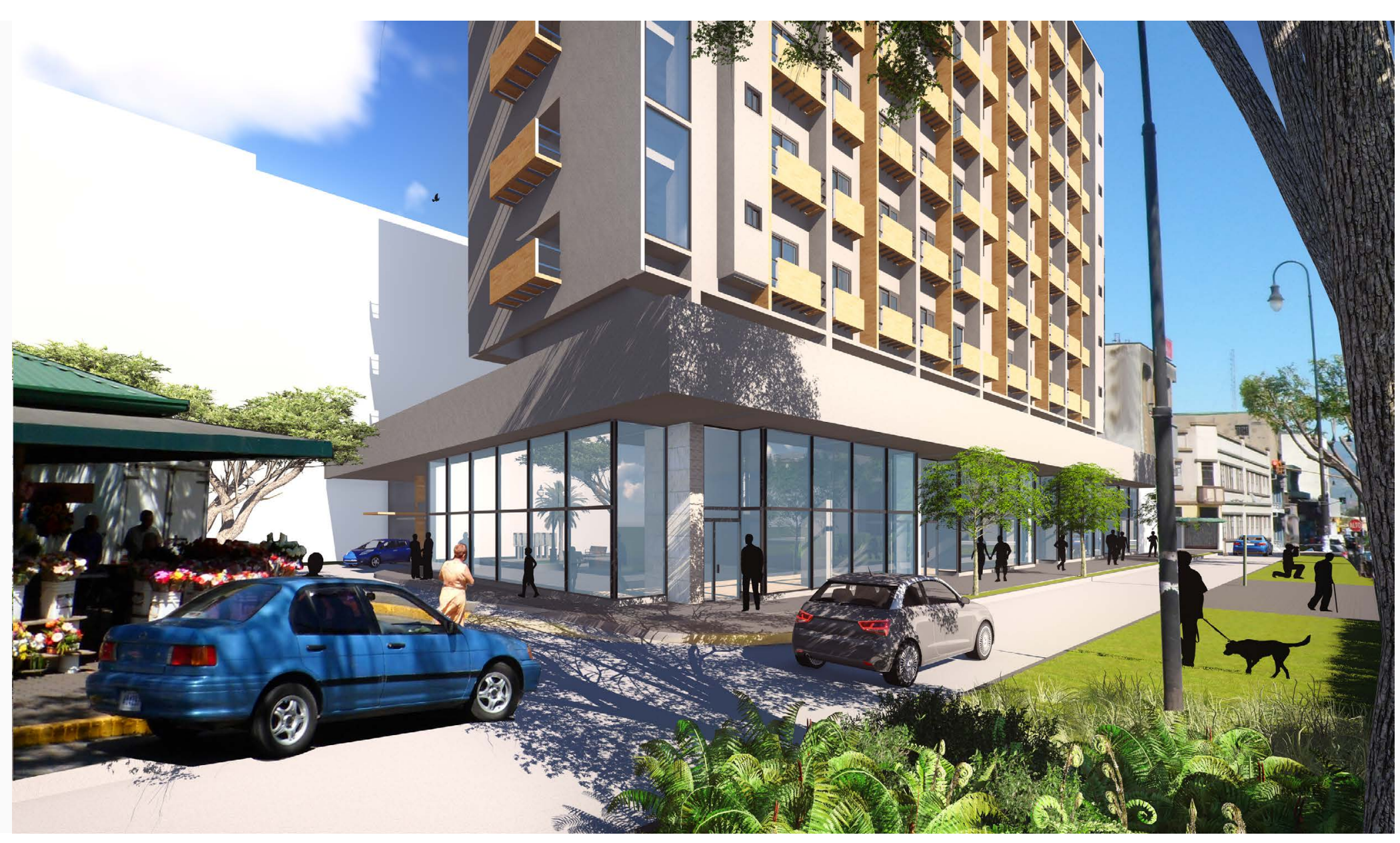

Figura 1. Vista Sureste: La imagen corresponde al costado sureste del anteproyecto de rehabilitación realizado en el edificio Plaza de La Artillería. La propuesta sugiere que estos edificios desocupados no son una limitación sino más bien una oportunidad para desarrollar un concepto de vivienda en altura, que integre las riquezas de la ciudad de San José y disponga de espacios verdes y recreativos a su alcance. 


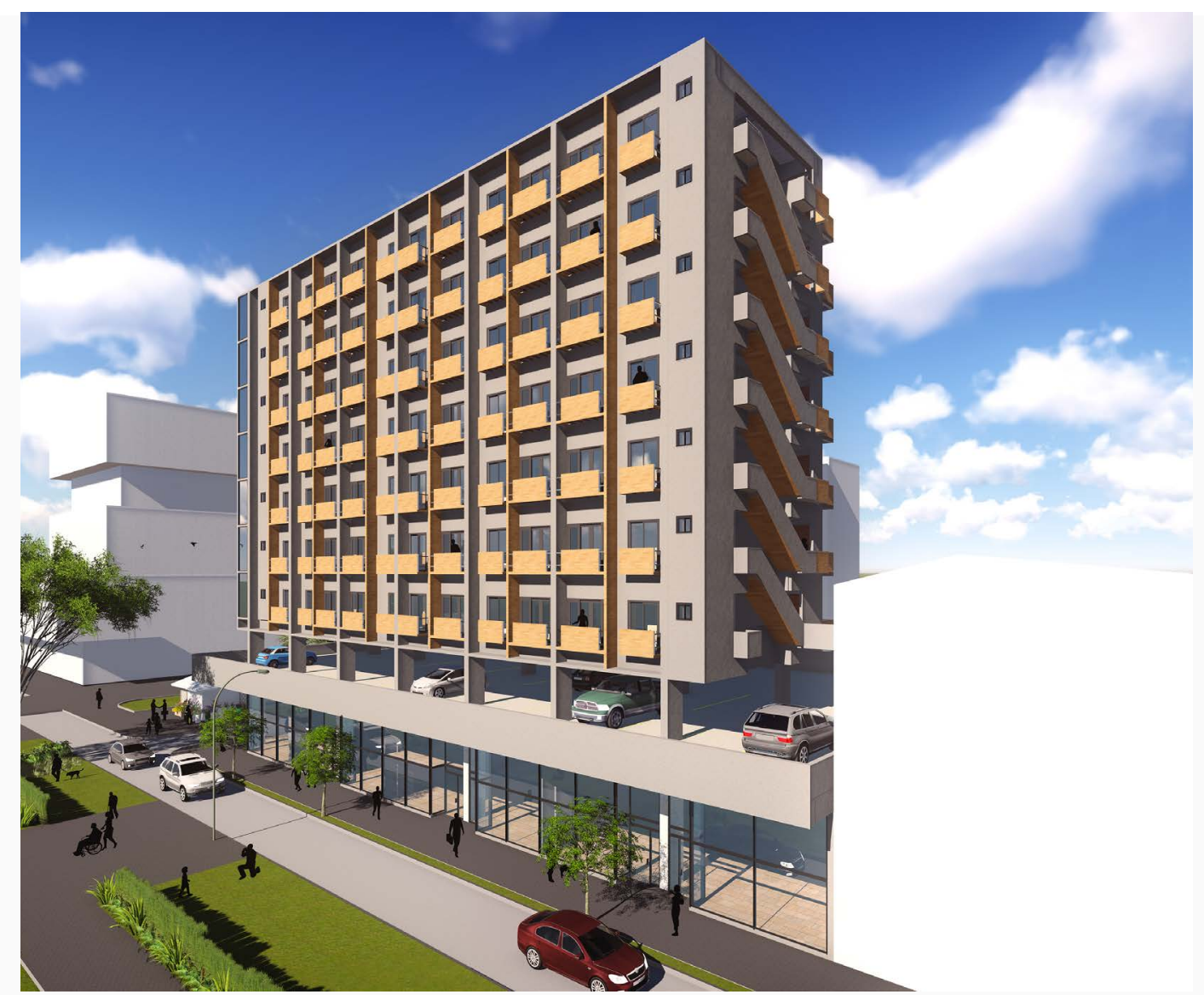

Figura 2. Vista Noreste: Globalmente no se está analizando la capacidad de la estructura, sin embargo se proponen mejoras locales a elementos para evitar comportamientos adversos, durante un sismo fuerte o en general. Una de las mejoras más significativas fue el de evitar el efecto de columna corta en la fachada este y se remueven los muretes preexistentes, creando un espacio más abierto e interactivo con su entorno.

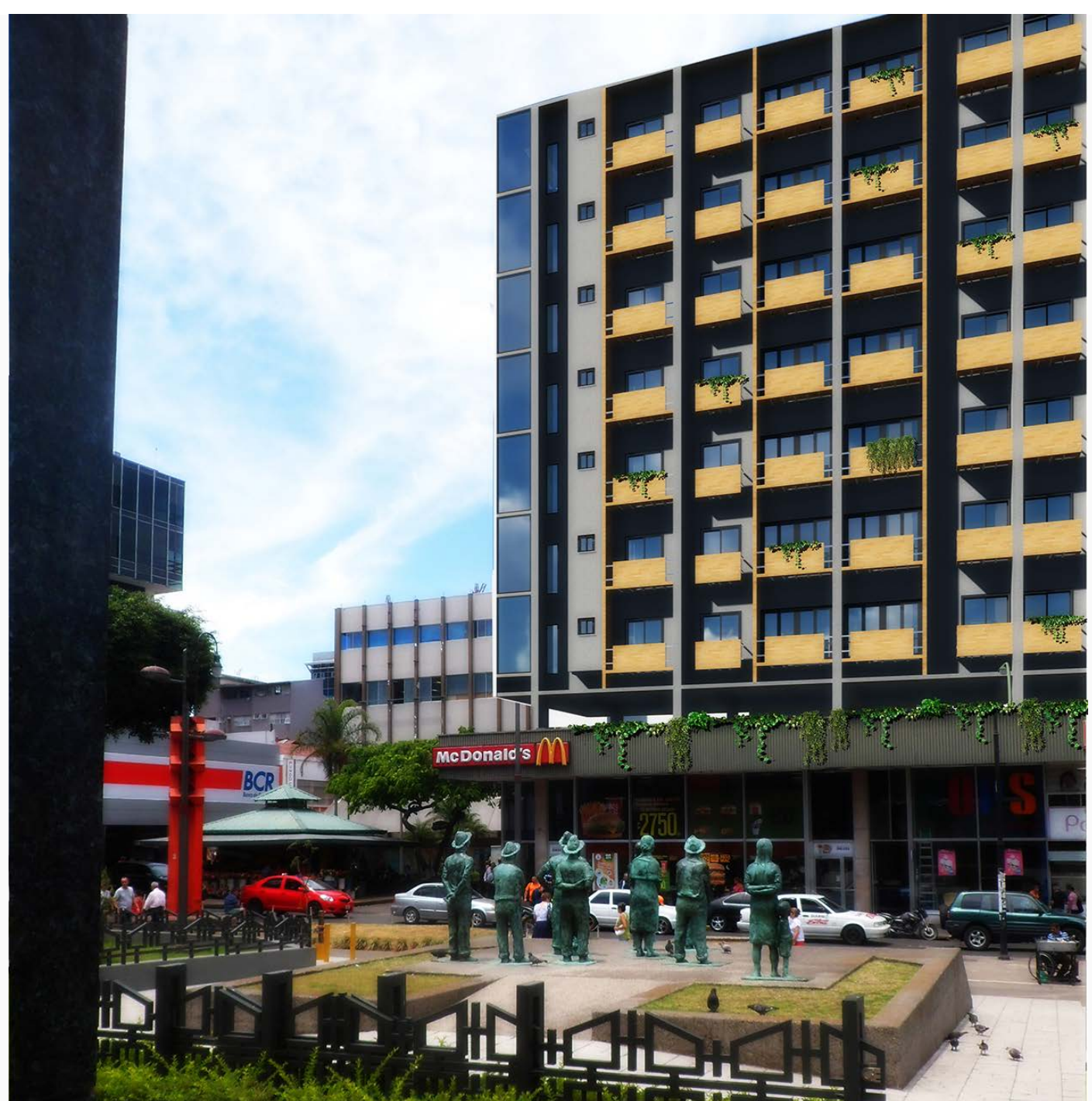

Figura 3. Fotomontaje vista desde el Banco Central de Costa Rica: Los balcones son parte integral de la vivienda y se añaden tanto al espacio de la sala como a los dormitorios. 

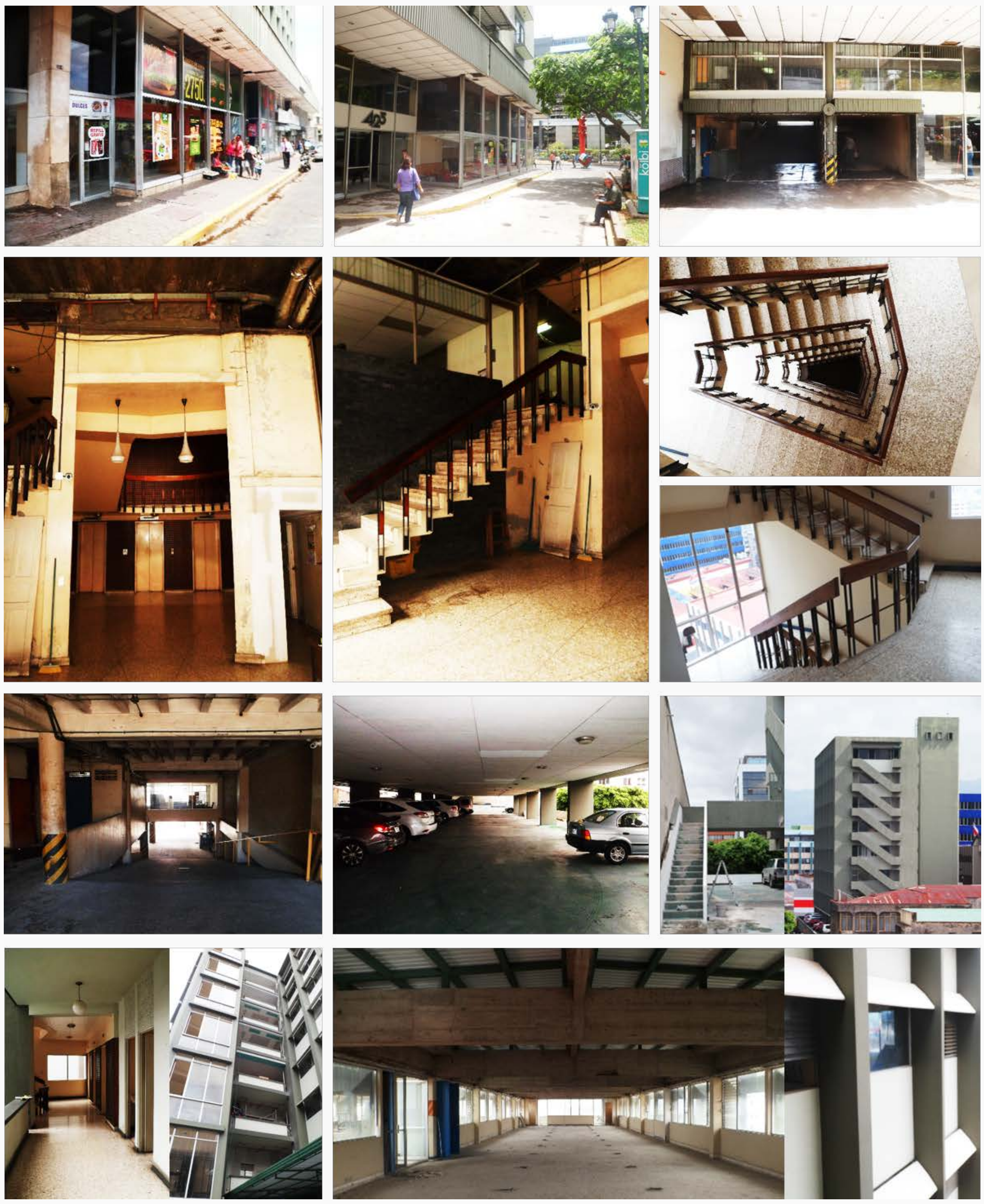

Figura 4. Collage levantamiento fotográfico de la Plaza de la Artillería: Se toma en cuenta el estado actual en el que se encuentra el edificio, y cualidades que se puedan explotar o desventajas que limiten el adecuado desarrollo del proyecto, como por ejemplo el estado de conservación, adaptabilidad, escaleras, estacionamientos, iluminación, entre otras. 


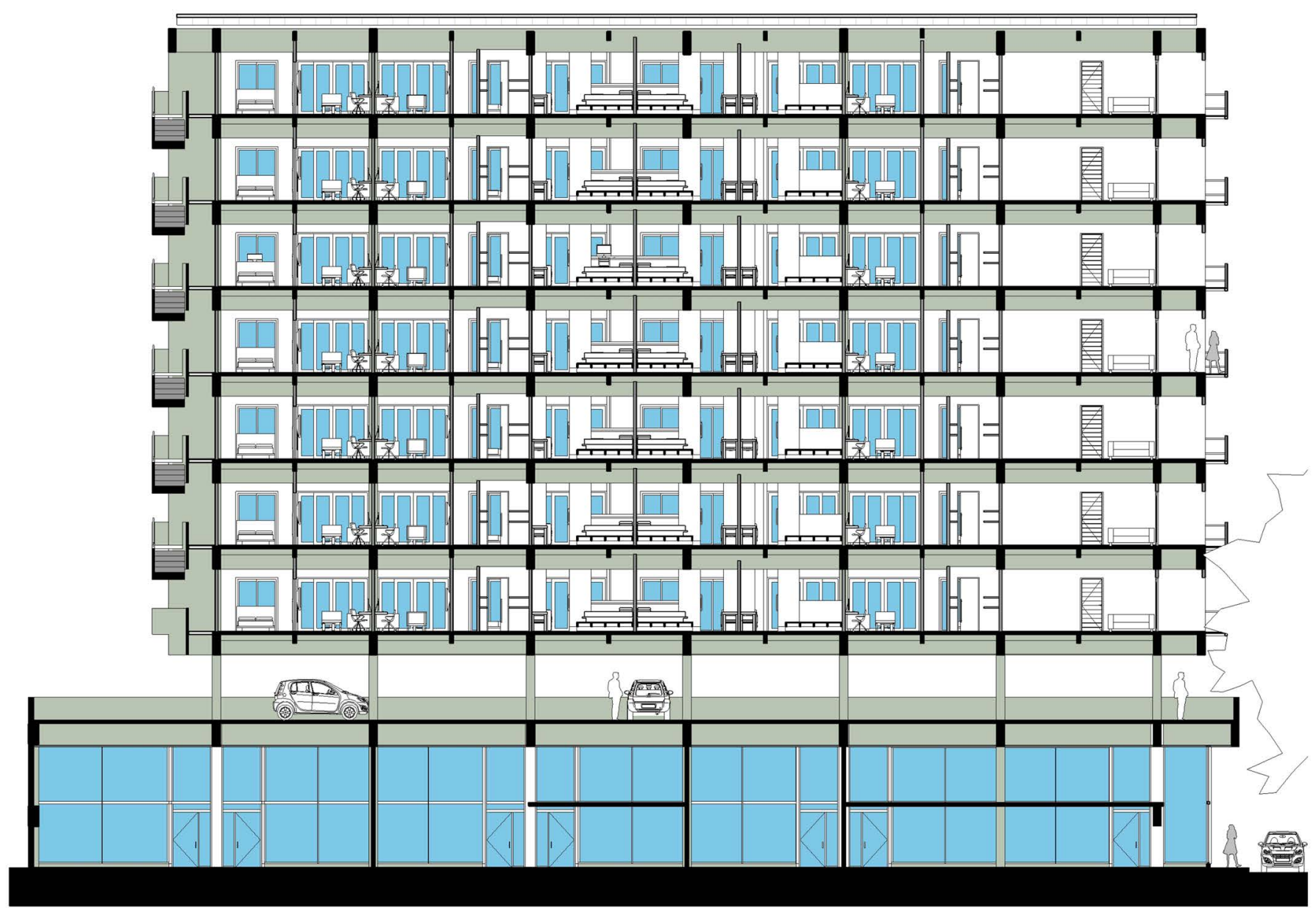

Figura 4. Corte Longitudinal

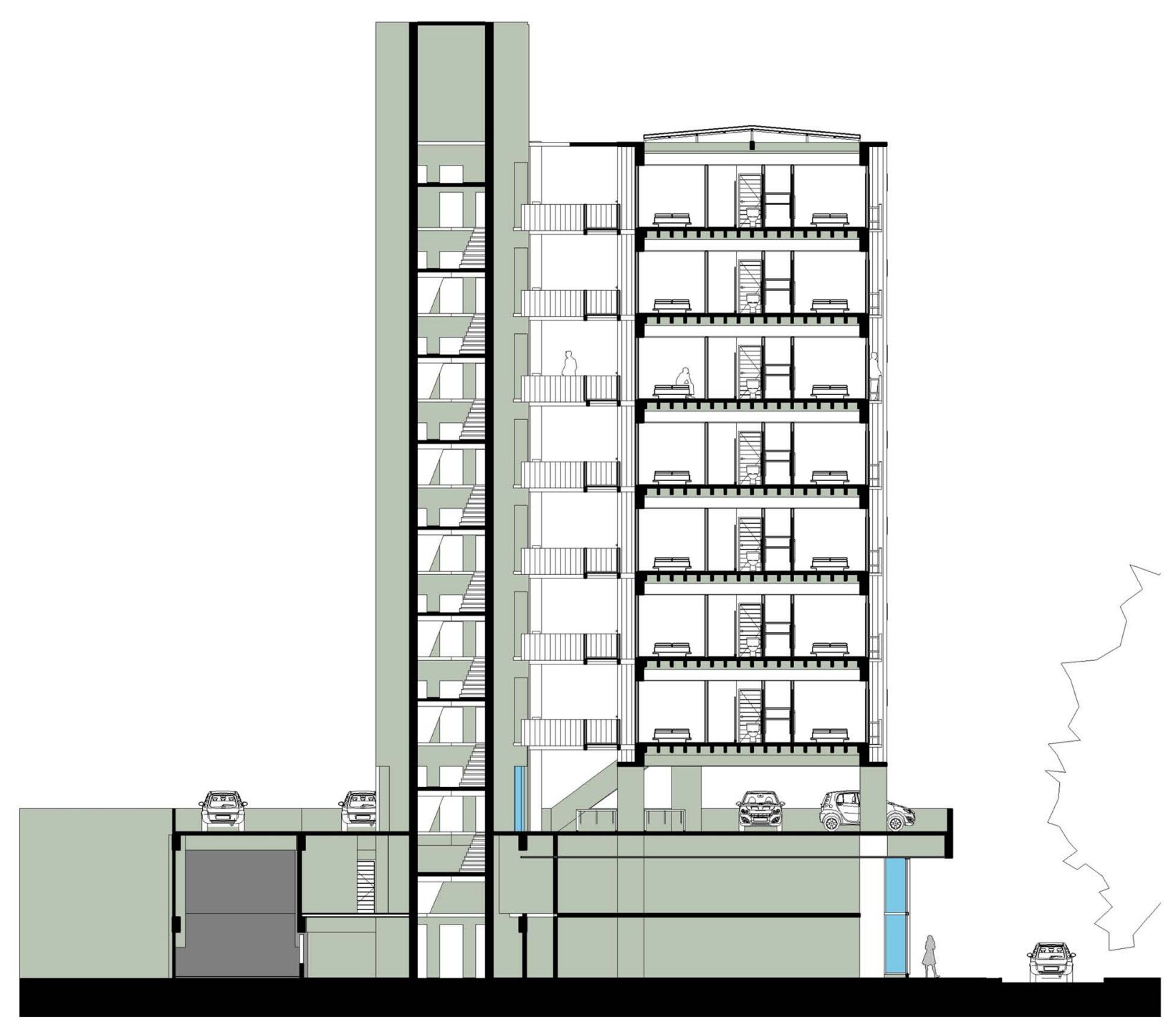

Figura 6. Corte transversal: La creación de una pasarela exterior nos da la oportunidad de tener doble fachada, lo que favorece a que todas las tipologías tengan una ventilación cruzada y una buena cantidad de luz natural. Todos los apartamentos tienen la misma orientación y ventilación cruzada; se democratiza el aspecto de cada vivienda 


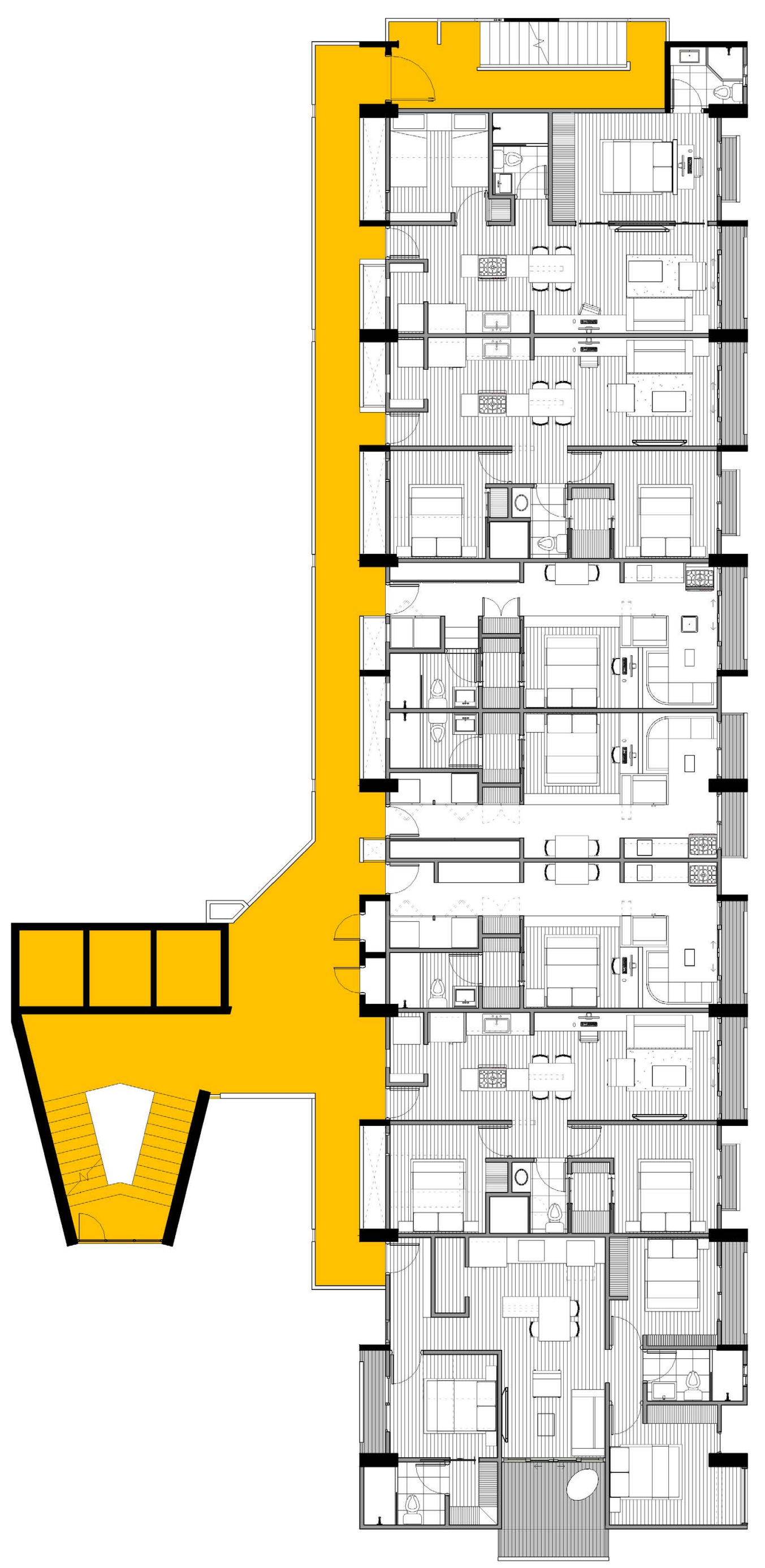

Figura 7. Planta Típica de apartamentos: El diseño de la propuesta busca utilizar la mayor cantidad del área disponible de la torre para los apartamentos, por lo que se propone incluir un acceso exterior y protegido, a manera de terraza, lo que se denomina pasarela exterior. Una circulación entre afuera y adentro, que genere un espacio fresco e interactivo antes de ingresar al interior de cada vivienda. 
Este artículo forma parte de:

\section{REVISTARQUIS}

Para más información, artículos, e instructivo de publicación, visite:

www.arquis.ucr.ac.cr/revistarquis.html 